OPEN ACCESS

Edited by:

Uday Kishore,

Brunel University London,

United Kingdom

Reviewed by:

Agnieszka J. Szczepek,

Charité Medical University of Berlin,

Germany

Robert Braidwood Sim

University of Oxford, United Kingdom

*Correspondence: Charlotta Kämpfe Nordström charlotta.kampfe.nordstrom@ akademiska.se

Wei Liu

Iwoo24@gmail.com

Specialty section: This article was submitted to

Molecular Innate Immunity,

a section of the journal

Frontiers in Immunology

Received: 27 June 2018 Accepted: 27 December 2018

Published: 01 February 2019

Citation:

Kämpfe Nordström C, Danckwardt-Lillieström N, Laurell G, Liu W and Rask-Andersen H (2019) The Human Endolymphatic Sac and

Inner Ear Immunity: Macrophage Interaction and Molecular Expression.

Front. Immunol. 9:3181.

doi: 10.3389/fimmu.2018.03181

\section{The Human Endolymphatic Sac and Inner Ear Immunity: Macrophage Interaction and Molecular Expression}

\author{
Charlotta Kämpfe Nordström ${ }^{1 *}$, Niklas Danckwardt-Lillieström ${ }^{1}$, Göran Laurell ${ }^{1}$, Wei Liu ${ }^{1 *}$ \\ and Helge Rask-Andersen ${ }^{2}$
}

${ }^{1}$ Section of Otolaryngology, Department of Surgical Sciences, Uppsala University Hospital, Uppsala, Sweden, ${ }^{2}$ Section of Otolaryngology, Department of Surgical Sciences, Head and Neck Surgery, Uppsala University Hospital, Uppsala, Sweden

Background: The endolymphatic sac (ES) is endowed with a multitude of white blood cells that may trap and process antigens that reach the inner ear from nearby infection-prone areas, it thus serves as an immunologic defense organ. The human $\mathrm{ES}$, and unexpectedly the rest of the inner ear, has been recently shown to contain numerous resident macrophages. In this paper, we describe ES macrophages using super-resolution structured fluorescence microscopy (SR-SIM) and speculate on these macrophages' roles in human inner ear defense.

Material and Methods: After ethical permission was obtained, human vestibular aqueducts were collected during trans-labyrinthine surgery for acoustic neuroma removal. Tissues were placed in fixative before being decalcified, rapidly frozen, and cryostat sectioned. Antibodies against IBA1, cytokine fractalkine (CX3CL1), toll-like receptor 4 (TLR4), cluster of differentiation (CD)68, CD11b, CD4, CD8, and the major histocompatibility complex type II (MHCII) were used for immunohistochemistry.

Results: A large number of IBA1-positive cells with different morphologies were found to reside in the ES; the cells populated surrounding connective tissue and the epithelium. Macrophages interacted with other cells, showed migrant behavior, and expressed immune cell markers, all of which suggest their active role in the innate and adaptive inner ear defense and tolerance.

Discussion: High-resolution immunohistochemistry shows that antigens reaching the ear may be trapped and processed by an immune cell machinery located in the ES. Thereby inflammatory activity may be evaded near the vulnerable inner ear sensory structures. We speculate on the immune defensive link between the ES and the rest of the inner ear.

Keywords: human, cochlea, macrophages, IBA1, structured illumination microscopy 


\section{INTRODUCTION}

The inner ear is segregated by a blood/labyrinth barrier and, like the brain, was generally thought to be immunologically inactive. Recent studies, however, have shown that a large population of IBA1-expressing macrophages reside in the human inner ear $(1,2)$. The cells have also been found to be present in the endolymphatic sac (ES), a separate portion of the inner ear located away from the cochlea and vestibular organs, which are related to hearing and balance. The ES is a part of the membranous labyrinth and is located in the petrous bone and in a dura duplicate near the cerebellum. The ES is connected to the rest of the inner ear by a filiform endolymphatic duct (ED, diameter $0.1-0.2 \mathrm{~mm}$ ) that runs to the ES in a bone channel called the vestibular aqueduct (VA). For clarity, the ED and ES is shown in a 3D reconstruction of a human inner ear cast of the Uppsala collection (3) (Figure 1). The ED and ES are generally thought to monitor homeostasis of the endolymph fluid surrounding the sensory hair cells. The fascinating ES has challenged ear researchers for years, and its function remains largely unknown.

Macrophage-lymphocyte interaction and mature plasma cells were earlier described in the guinea pig ES, using transmission electron microscopy (4-6), which supports the notion of local immune responsiveness in the human ES. Arnold et al. (7) found IgA both in the lumen of the human ES and in perisaccular plasma cells and Bui et al. (8) described subpopulations of lymphocytes, macrophages, and plasma cells. The existence of an immunologic route from the middle to the inner ear and from there to the ES was postulated by Ikeda and Morgenstern (9). The ES contains lymphocytes and plasma cells; and it is thought to act as an immunologic defense organ for the inner ear $(4,5,8,10)$. This idea was supported by Danckwardt-Lillieström et al. (11) who found microorganisms (Mycoplasma pneumoniae) in the lumen of the human ED, with signs of being processed. Further evidence of potential immune mechanisms was demonstrated by ablation of the ES, which lead to diminished secretion of specific antibodies in the perilymph and reduced immune activity after inner ear antigen challenge $(6,10,12-16)$. Tomiyama and Harris (6) suggested that the ES plays a role for both systemic and local antibody responses. Their findings indicated that certain inner ear disorders may be immune-system related and treatable with immunosuppressive agents (10).

Moreover, Möller et al. (17) studied the human ES and found gene expression for both the cellular and humoral innate immune-system, including toll-like receptors (TLR) 4 and 7, beta-defensin, and lactoferrin. These findings provided molecular evidence of an immunological capacity of the ES to recognize and process antigens for immune responses. Betadefensin and lactoferrin are potent molecules against invading pathogens and were found to be expressed by the ES epithelium,

\footnotetext{
Abbreviations: ED, endolymphatic duct; ES, endolymphatic sac; E, endolymph; EDTA, ethylene-diamine-tetra-acetic acid; SR-SIM, super-resolution structured illumination fluorescence microscopy; IBA1, ionized calcium binding adaptor molecule 1; VA, vestibular aqueduct; MHCII, major histocompatibility complex type II.
}

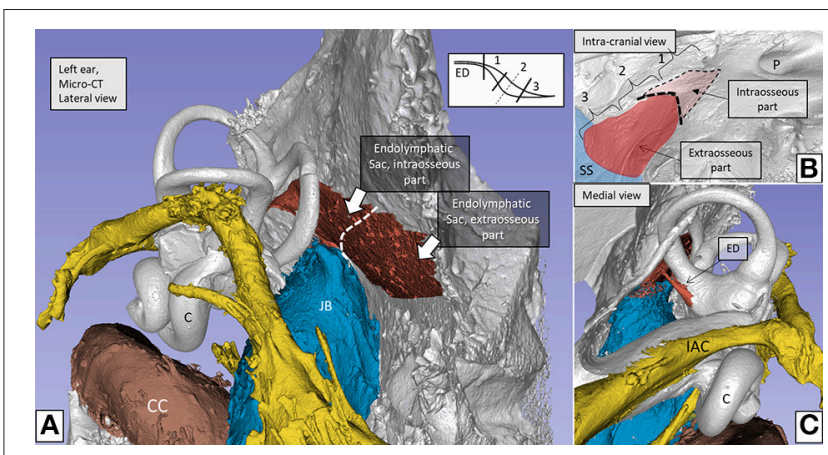

FIGURE 1 | (A) Micro-CT and computer 3D reproduction of a left human inner ear silicon cast. The cochlea (C) and semicircular canals are seen together with the vestibular aqueduct (red). Facial nerve canal is yellow and veins are blue. The vestibular aqueduct (red) houses the endolymphatic duct (ED) and sac. The sac consists of an intraosseous part located inside the temporal bone and an extra-osseous part located on the posterior slope of the petrous pyramid within the dura. (B) The sac exits through an opening in the bone (external aperture of the VA, interrupted line in $\mathbf{A}, \mathbf{B}$ ), and it often extends over the sigmoid sinus (SS). (C) The ED connects the sac with the rest of the inner ear. The intra- and extra-osseous parts of the sac were investigated in the present study. The sac is divided into a proximal (1), an intermediate (2), and a distal part (3). 1 and 3 have a smooth, single-cell layered epithelium, while the intermediate part (2) has a rugose multi-layered epithelium with secretory-like tubules. Demonstration of the bony surface in (B) is possible by using a transparency paradigm within the 3D program. C, Cochlea; JB, Jugular bulb; SS, Sigmoid sinus; IAC, Internal auditory canal; P, Internal acoustic porous; CC, Carotid canal.

which strongly supported the authors' view that the ES acts as an immunological entity of the inner ear.

Here, we used super-resolution structured illumination microscopy (SR-SIM), together with confocal microscopy to analyze the molecular structure of the human ES and its possible role for inner ear immunity. Freshly fixed human ESs and archival cochleae were analyzed after ethical permission was obtained. The tissue was processed with primary antibodies against IBA1, MHCII, CX3CL1 (fractalkine), CD68, CD4, CD8, CD11b, TLR4, vimentin, and type IV collagen. Highresolution fluorescence microscopy showed MHCII expressing macrophages and interaction with neighboring $\mathrm{CD} 68, \mathrm{CD} 4$, and TLR4 positive cells. The possibility of a functional link between the macrophage systems in the ES and inner ear sensory organs $(2,18-20)$ is discussed.

\section{MATERIALS AND METHODS}

\section{Ethics Statement}

The study of discarded human tissue was approved by the local ethics committee (Etikprövningsnämnden Uppsala, no. 99398, 22/9 1999, cont, 2003, no. C254/4; no. C45/7 2007, Dnr. 2013/190), and patient consent was obtained. The study adhered to the rules of the Declaration of Helsinki. Archival sections from adult cochleae were used $(21,22)$.

\section{The Human Vestibular Aqueduct}

Fresh tissue samples of the human ES were collected during surgery for vestibular schwannoma using the trans-labyrinthine 
approach. No data on age, gender, or audiometric results were retrieved. Five ESs with surrounding bone tissue were dissected using diamond drills of various sizes. A thin shell of bone was saved around the ES in order to protect the epithelial surface. Both the intra- and extra-osseous parts of the ES were analyzed. The ED and the part of the ES located on the sigmoid sinus could not be investigated. The first part of the ES is named "proximal," the second part, "intermediate," and the third part, "distal" (1-3 in Figure 1B). The intermediate part is also termed "rugose" since its epithelium is folded and contains secretory-like epithelial tubules (23). In the operating room the tissue was immediately placed in $4 \%$ paraformaldehyde in PBS [1.06 mM KH2PO4, 2.97 mM Na2HPO4, $155.17 \mathrm{mM} \mathrm{NaCl}, \mathrm{pH}$ 7.4 (ThermoFisher, cat no 10010-015)]. After a 24-h period spent in fixative, the specimens were washed in PBS and then placed in $0.5 \mathrm{M}$ Na-ethylene-diamine-tetra-acetic acid (EDTA) solution (Medicago AB, Uppsala, Sweden) buffered in PBS to $\mathrm{pH} 7.2$ for decalcification. The EDTA solution was changed every 45 days until the decalcification process was completed, which took $\sim 3$ weeks. The decalcified ESs were rinsed with PBS and placed in $20 \%$ sucrose solution dissolved in PBS overnight at $4{ }^{\circ} \mathrm{C}$. The ESs were embedded in Tissue-Tek (OCT Polysciences) for frozen sections. The ESs were rapidly frozen and sectioned at 8-10 $\mu \mathrm{m}$ using a Leica cryostat microtome. The frozen sections were collected onto glass slides (SuperFrost ${ }^{\circledR}$ Plus, MenzelGläzer, Braunschweig, Germany) and stored below $-70^{\circ} \mathrm{C}$ before immunohistochemistry was conducted.

\section{Antibodies and Immunohistochemistry}

Table 1 shows the series of antibodies used in the present study. IBA1 polyclonal antibody (Thermo Fisher Scientific) from rabbit was used at a dilution of 1:100. The specificity of the antibody was proven by IBA1 antibody blotting (24). The fractalkine antibody used was a monoclonal antibody (1:100, mouse, MAB3651, R\&D Systems). This antibody specificity was verified by western blotting (25). The CD68 antibody used was a monoclonal antibody (1:50, mouse, NB100-683, Novus), and the specificity was proven by western blotting (26). For the following antibodies, specificity was proven by the following:

- MHCII-flow cytometry (27).

- TLR4-western blot (www.thermofisher.com).

- CD11b-flow cytometry (28).

- CD4-neutralization (29).

- CD8 $\alpha$-flow cytometry (30).

Antibody against collagen IV was used to discriminate the basal lamina and antibody against vimentin to visualize the epithelial cells (31). The immunohistochemistry procedures performed on the sections have been described in previous publications (22, 32). Briefly, the slide-mounted sections were incubated with an antibody solution under a humidified atmosphere at $4^{\circ} \mathrm{C}$ for $20 \mathrm{~h}$. After rinsing with PBS three times for $5 \mathrm{~min}$ each, the sections were incubated with secondary antibodies conjugated to Alexa Fluor 488 and 555 (Molecular Probes, Carlsbad, CA, USA) for $2 \mathrm{~h}$ at room temperature. The primary and secondary antibodies were diluted in $2 \%$ bovine serum albumin (BSA) dissolved in PBS. The sections were then counter-stained with the nuclear stain DAPI (4', 6-diamidino-2-phenylindole dihydro-chloride) for $5 \mathrm{~min}$, were rinsed with PBS $(3 \times 5 \mathrm{~min})$, and were mounted with Vectashield (Vector Laboratories, Burlingame, CA, USA) mounting medium. The sections were rinsed with PBS $(3 \times$ 5 min) and mounted with ProLong ${ }^{\mathrm{TM}}$ Gold Antifade Mountant (Invitrogen, Carlsbad, CA, USA) as well as the specified cover glass (Mänzel-Gläser, Braunschweig, Germany) required for optically matching the microscope objectives.

Primary and secondary antibody controls and labeling controls were used to exclude endogenous labeling or reaction products (33). The control sections were incubated with $2 \%$ BSA, omitting the primary antibodies. The control experiment revealed no visible staining in any structure of the cochleae. Both wide-field and confocal fluorescence imaging software exhibited sensitive fluorescent saturation indications, thereby avoiding overexposure. In addition, archival sections of human cochlea were analyzed according to the methods described in Liu et al. (2).

\section{Imaging and Photography}

The stained sections were first investigated with an inverted fluorescence microscope (Nikon TE2000) equipped with a spot digital camera with 3 filters (for emission spectra maxima at 358,461 , and $555 \mathrm{~nm}$ ). Image-processing software (NIS Element BR-3.2, Nikon), including image merging and a fluorescence intensity analyzer, was installed on a computer system connected to the microscope. For the laser confocal microscopy, we used the same microscope equipped with a three-channel laser emission system. The optical scanning and image-processing tasks were performed using the Nikon EZC1 (ver. 3.80) software and included the reconstruction of the Z-stack images into projections and 3-D images. The SRSIM was performed using a Zeiss Elyra S.1 SIM system and a $63 \mathrm{x} / 1.4$ oil Plan-Apochromat objective (Zeiss), a sCMOS camera (PCO Edge), and the ZEN 2012 software (Zeiss). Multicolor SRSIM imaging was achieved with the following laser and filter setup:

- first channel: $405 \mathrm{~nm}$ laser excitation and BP 420-480 + LP 750 filter

- second channel: $488 \mathrm{~nm}$ laser excitation and BP 495-550 + LP750 filter

- third channel: $561 \mathrm{~nm}$ laser excitation and BP 570-620 + LP 750 filter

- forth channel: $647 \mathrm{~nm}$ laser excitation and LP 655 filter

To maximize the image quality, five grid rotations, and five phases were used for each image plane and channel. The grid size was automatically adjusted by the ZEN software for each wavelength of excitation. The SR-SIM images were processed with the ZEN software using automatic settings and theoretical point spread function (PSF) calculations.

From the SR-SIM dataset, 3-D reconstruction was performed with Imaris 8.2 (Bitplane, Zürich, Switzerland). A bright-field channel was merged with fluorescence to visualize the cell borders. The microscope is capable of achieving a lateral $(\mathrm{X}-\mathrm{Y})$ resolution of $\approx 100 \mathrm{~nm}$ and an axial $(Z)$ resolution of $\approx 300 \mathrm{~nm}$ (34). The resolution of the SIM system in BioVis (Uppsala) 
TABLE 1 | Antibodies used in the present study.

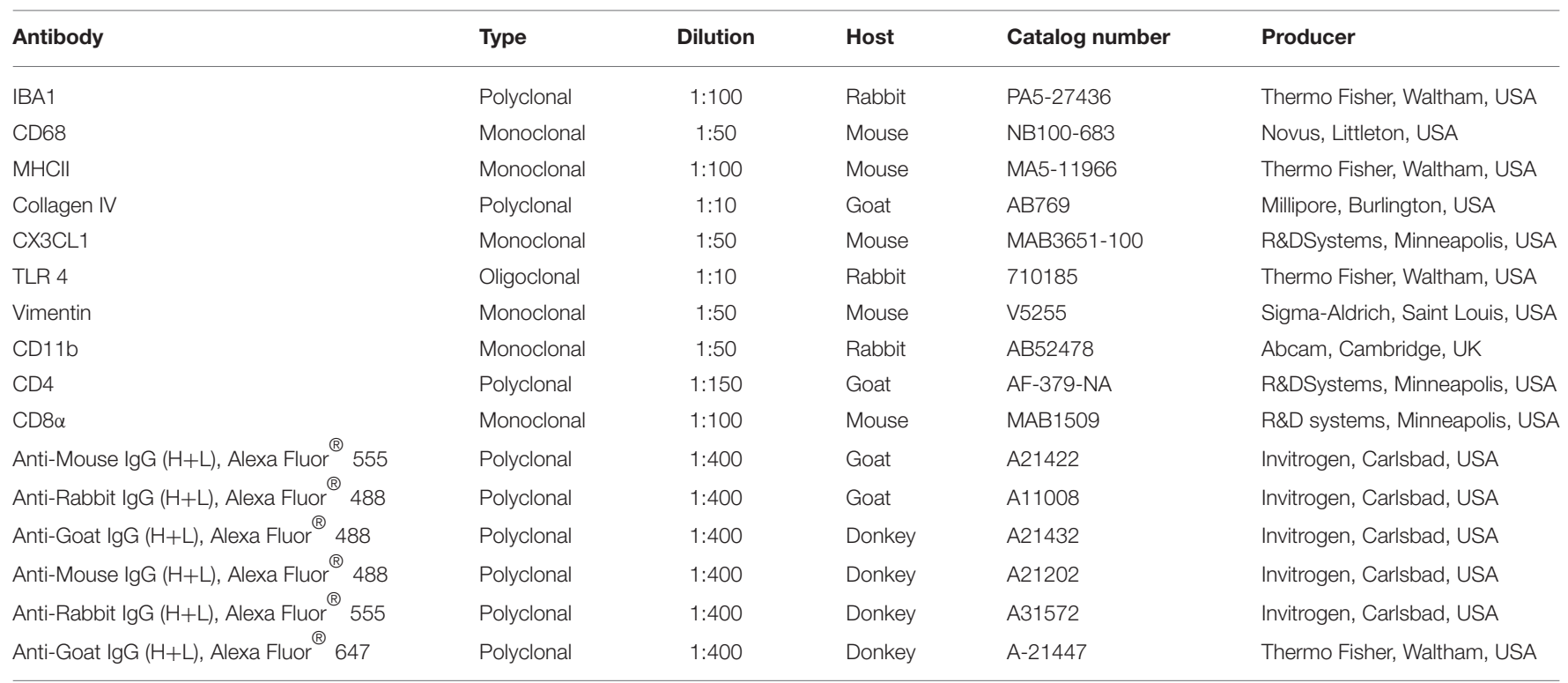

was measured with sub-resolution fluorescent beads $(40 \mathrm{~nm}$, Zeiss) in the green channel (BP 495-550 + LP750). An average PSF value was obtained from multiple beads with the built-in experimental PSF algorithm of the ZEN software. The typical resolution of the system was $107 \mathrm{~nm}$ in the $X-Y$ plane and $394 \mathrm{~nm}$ in the $\mathrm{Z}$ plane. 3-D reconstructions of collagen IV and IBA1 protein expression were conducted. Both signals were reconstructed by a surface rendering mode using the Imaris 8.2 software.

SIM or structured illumination microscopy is a wide-field technique that is based on the Moire effect of interfering fine striped patterns of excitation with sub-diffraction features in the sample emission. This can be compared with the confocal technique where the fluorescence light is detected only at the focal plane. The resolution is twice as big and offers better possibilities to demonstrate proteins at a subcellular level. Combined with confocal microscopy the techniques allow overviews of protein distribution in the tissue as well as a more detailed cellular localization.

\section{RESULTS}

Maintaining the bony wall of the VA at drilling resulted in improved structural preservation of the vulnerable ES tissue, which is well suited for SR-SIM immunohistochemistry after decalcification. The pattern of expression of all the proteins stained for in the study was similar in all 5 specimens.

\section{IBA1 and Fractalkine Expression}

SR-SIM and confocal microscopy showed a large number of IBA1-expressing cells in all the investigated parts of the ES (Figures 2-8). IBA1 cells resided both in the sub-epithelial tissue and in the epithelium. A surprisingly large number of perisaccular connective tissue cells expressed IBA1 (Figure 2C). These cells were elongated and branched, while others were stellate-like with long cross-sectioned branches. The cells' nuclei expressed IBA1, which made them distinguishable from fibrocytes (Figures 2A,B, 3A). In the epithelium, the cells were located between and beneath the epithelial cells; in addition, the epithelial cells themselves expressed IBA1 (Figures 3C, 6, 7). Some IBA1 cells showed signs of trans-epithelial migration, and were expelled into the sac lumen (Figures 3B,D). Large aggregations of IBA1 cells could be demonstrated at some places (Figure 4). The intra-epithelial location of the IBA1 cells could be documented by collagen IV immunostaining of the basal lamina (BL; Figure 5). The BL was often irregular and fragmented at these sites, with accumulated remains (Figure 5).

The epithelial cells expressed the chemokine fractalkine (Figure 2B). The expression varied between different cells and was mostly diffuse and intra-cytoplasmic. Some sub-epithelial fibrocytes also expressed fractalkine (Figure 3C).

\section{Expression of IBA1 and Major Histocompatibility Complex Type II}

Many epithelial (Figures 6, 7) and non-epithelial cells (Figure 6, Supplementary Figure 1) co-expressed IBA1 and MHCII. Those appearing in the epithelium appeared to be both free intraepithelial cells and true epithelial cells, especially in the secretorylike tubules of the intermediate ES (Figure 6). Among the epithelial cells, MHCII was mostly expressed in the apical membrane. Some of these cells contained large vesicles (23 microns) that occasionally opened to the endolymph space (Figure 7). The epithelial IBA1 cells also contained small aggregates of MHCII scattered in the cytoplasm (Figure 7B). 


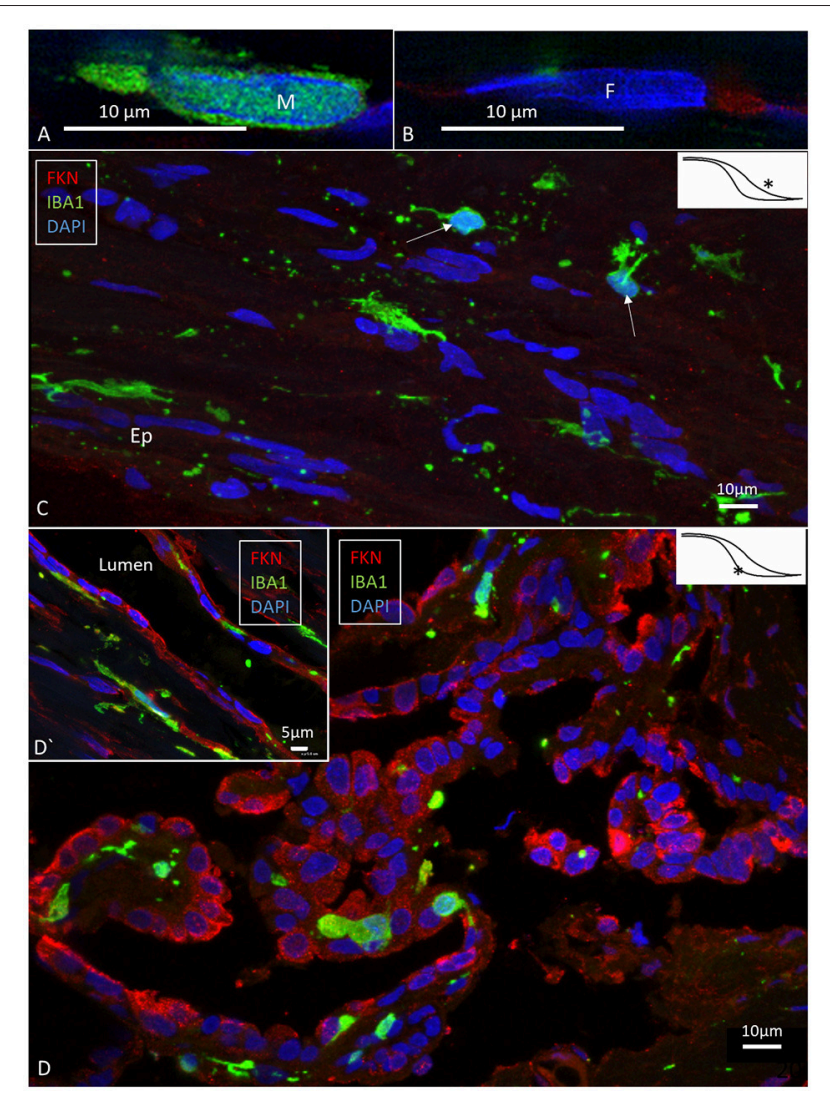

FIGURE 2 | SR-SIM (A,B) and confocal fluorescence microscopy (C,D) of the human ES. (A,B) show the difference in nuclear expression of IBA1 protein in macrophages (A) and fibrocytes (B) in the peri-saccular tissue. (C) The sub-epithelial tissue in the intraosseous part of the ES displays a large number of variously shaped IBA1-positive cells. In two of these cells (arrows), the typical nuclear staining can be seen. Several thin cross-sectioned ramifications of IBA1 cells are visible. (D) The epithelium also contains a large number of IBA1 cells, located both between and beneath epithelial cells (inset $\mathbf{D}^{\prime}$ ). The epithelial cells express the chemokine fractalkine. *Shows location in the ES.

\section{Expression of Toll-Like Receptor 4, CD68, and CD11b}

High-resolution fluorescence microscopy also disclosed expression of toll-like receptor 4 (TLR4) among the subepithelial cells in the intermediate ES (Figures 8A-C). These cells did not co-express IBA1. TLR4 was expressed both in the cell membrane and in the cytoplasm. In some cells the nuclei also expressed TLR4 (Figure 8C). A few sub-epithelial cells expressed CD68 (Figure 8D), which was occasionally co-expressed with IBA1. Several migrating cells expressed CD68 and CD11b together with MHCII (Figure $\mathbf{8 H}$ ). Round cells expressing CD4 and $\mathrm{CD} 8$ were found in the ES, with more CD4+ than CD8+ cells (Figures 8E-G). Physical interaction between a CD4+ and an IBA1 cell was noticed (Figure 8G).

\section{IBA1 and Major Histocompatibility Complex Type II in the Human Cochlea}

To realize if IBA1 cells in the human cochlea also expressed MHCII, archival sections were stained. Numerous IBA1positive macrophages expressed MHCII in the stria

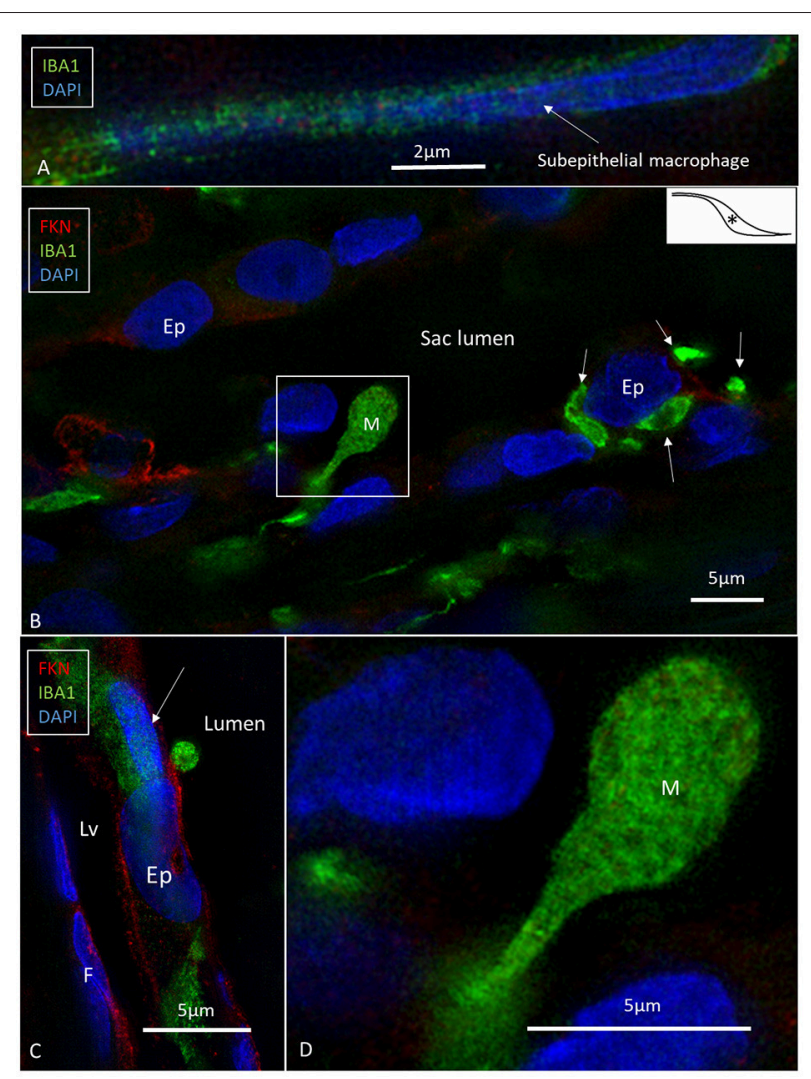

FIGURE 3 | SR-SIM of human ES near the external aperture of the VA. (A) An elongated sub-epithelial cell expressing IBA1. (B) IBA1-positive cells are located both sub-epithelial and within the epithelium (Ep). One cell seems to have been loosened and expelled into the lumen of the ES. The framed area is magnified in (D). One epithelial cell is surrounded by several IBA1-positive cells (arrows). (C) An IBA1 cell is located next to an epithelial cell (arrow). Sub-epithelial fibrocytes (F) and epithelium express fractalkine. LV, lymphatics; $D$, The framed area in B magnified to show an IBA1 cell, presumably being expelled into the lumen; M, Macrophage. *Shows location in the ES.

vascularis and spiral ganglion (Figure 9). The cells contained cytoplasmic aggregates of MHCII (Figure 9, lower inset) and their slender processes often embraced the vessels. Fewer, but similarly stained cells were detected in the spiral ligament. TLR4 was expressed in the stria vascularis (not shown).

\section{DISCUSSION}

\section{Structured Illumination Microscopy and the Human Endolymphatic Sac}

This is the first study to use super-resolution immunohistochemistry of the human ES, which showed the spectacular organization of resident IBA1-positive macrophages and the molecular expression in great detail. The large quantity of macrophages was unexpected, since most of the sub-epithelial cells seemed to represent fibrocytes, while the SR-SIM immunohistochemistry showed them to be resident macrophages. The IBA1 marker protein (ionized calcium binding adaptor molecule 1) is an actin cross-linking protein 


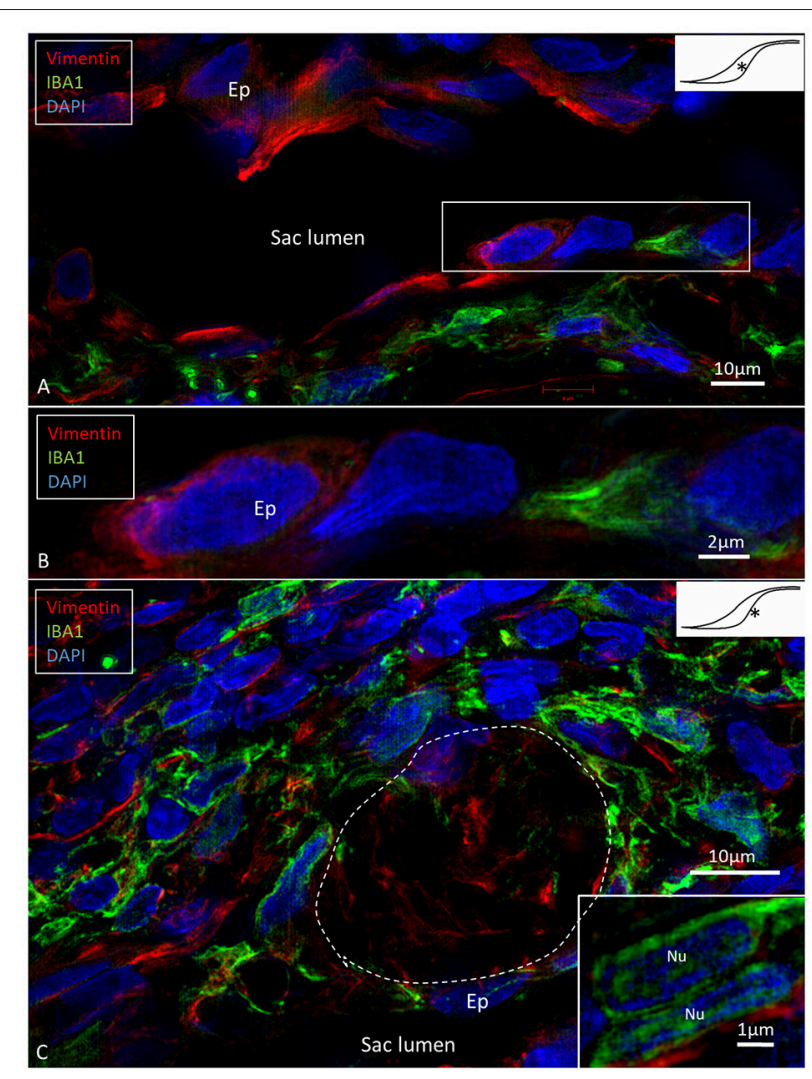

FIGURE 4 | SR-SIM of epithelial conglomerate at the intra-osseous part of the ES. (A,B) Some epithelial cells (Ep) express the intermediate filament vimentin. (C) The accumulation of IBA1 cells is visible beneath the epithelium and around several vimentin-positive cells. Inset, The IBA1 cells show characteristic nuclear (Nu) staining. *shows location in the ES.

associated with membrane ruffling and phagocytosis $(35,36)$. It is expressed in both reactive and quiescent microglial cells (37). Previous studies have yielded similar findings in the human inner ear; several resident macrophages were found to be positive for markers CD163, IBA1, and CD68 $(1,2)$. The cells were localized in the inner ear under steady-state conditions (19, 38-40), suggesting that the inner ear contains immune-competent cells that may activate both innate and adaptive immune responses. IBA1 was typically expressed in the nuclei, the cytoplasm, and in small cytoplasmic specializations against adjacent tissue $(2,41)$. The immune state of the inner ear was not believed to be influenced by the benign cranial tumor in the internal ear canal. Cochlear macrophages are thought to derive from bone marrow myeloid precursors, and they do not seem to undergo self-renewal during life (42). The term "microglia" may therefore not be an appropriate term since these cells have different ontogeny, morphology, and surface markers (43).

\section{Vestibular Schwannoma and Tissue Collection}

The collected tissue was from patients with benign tumors located in the internal acoustic canal. Therefore, one cannot rule

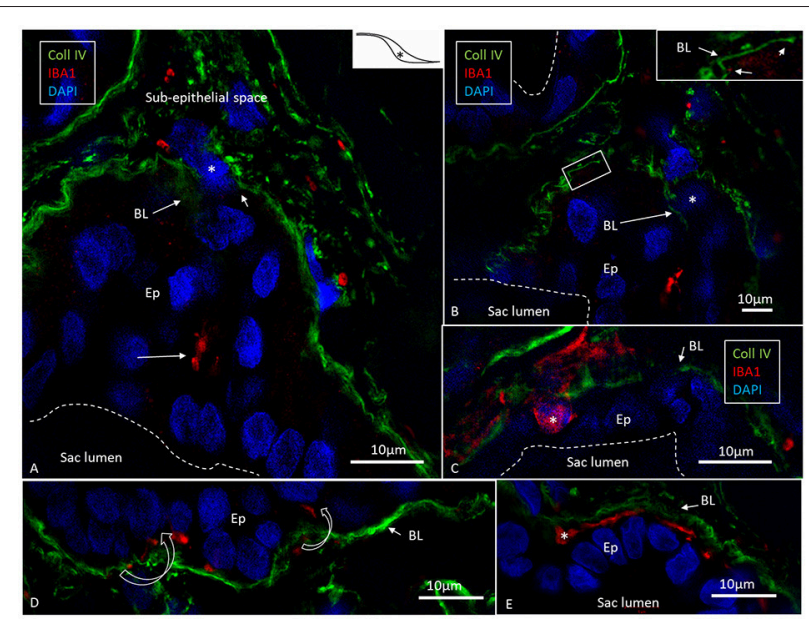

FIGURE 5 | Expression of IBA1 cells and collagen IV. SR-SIM of the intra-osseous part of the ES showing several epithelial tubules. (A) IBA1 cells are located in the epithelium (Ep) as well as in the sub-epithelial space. (B) Adjacent section shows discontinuous basal lamina (BL) and trans-epithelial migration of one IBA1-neagtive cell $\left(^{*}\right)$. (C) Large IBA1 cell $\left(^{*}\right)$ crosses the $B L$ and epithelium. (D,E) IBA1 cells located between the $B L$ and epithelial cells. Note the extensive fragmentation of BL collagen IV expression in the sub-epithelial space. *Shows location in the ES.

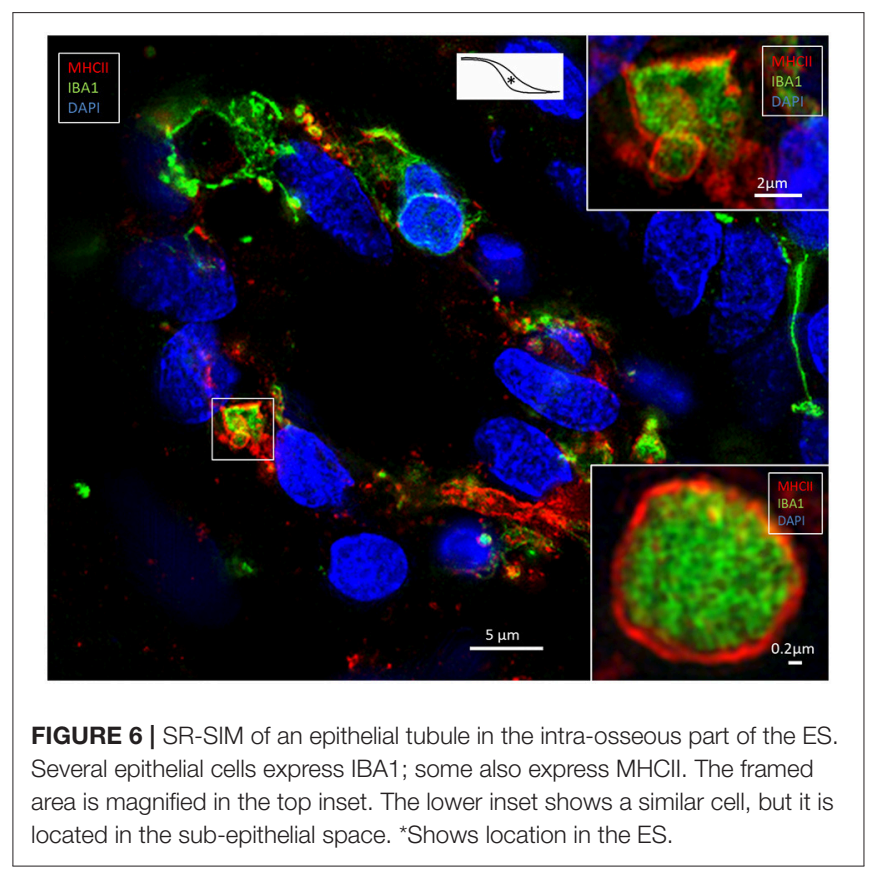

out the possibility that the immune state of the inner ear could be influenced by this pathology, even though located at some distance. However, the similar findings of IBA1 cells made by O'Malley et al. (1) using alternate histological techniques would seem to refute this. Their material was from archives of different donated temporal bones with no tumors. Likewise, some of these findings were made in experimental animals (Okano et al.) (20). 


\section{Blood-Labyrinth Barrier and Fractalkine Signaling (CX3CL1/CX3CR1)}

The human inner ear is sheltered by hard bone, and it is separated by a so-called blood-labyrinth barrier, which is equivalent to the blood-brain barrier and may be crucial for the immune defense. In the brain, bone marrow-derived macrophages are

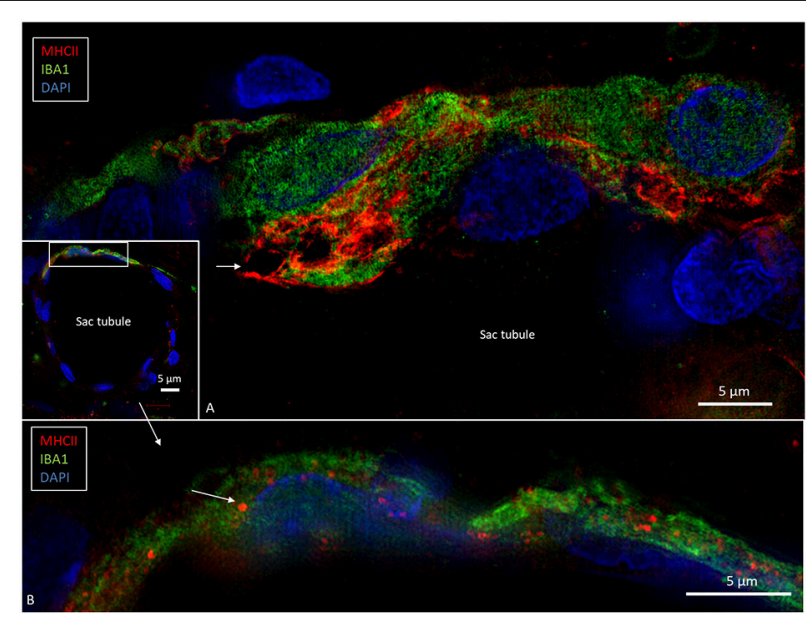

FIGURE 7 | SR-SIM of epithelial tubules in the intra-osseous part of the ES. (A) Several IBA1-positive cells are present in the epithelium and seem to constitute an integral part of the epithelium. The cells express MHCll. Large endocytic vesicles (arrow) express MHCII. (B) The framed area of the inset is shown under a higher magnification; some epithelial cells express IBA1 as well as $\mathrm{MHCll}$ (arrow). restricted to regions lacking a blood-brain barrier. The barrier consists of tight junctions separating the endolymph from the extracellular tissue. The spiral ganglion and the ES contain fenestrated vessels suggesting that they are not embraced by the blood-labyrinth barrier (44). Consequently, blood-borne leukocytes may migrate more readily into the ES. Hirose et al. and Kaur et al. $(18,40)$ discovered that cochlear injury and selective loss of cochlear hair cells increase the number of marrow-derived monocyte/macrophage lineage cells in the cochlea, including the auditory nerve, and spiral ligament. Fractalkine, a chemokine normally found in neural cells, was found to play a significant role for the attraction through the macrophages' receptor expression. Signaling induces chemotactic cell adhesion. As well it was essential to recruit macrophages by noise, ototoxic drugs, age, and diphtheria toxin induced selective hair cell degeneration (18, 39, 40, 43, 45-52). Mice lacking the receptor (CX3CR1) showed a reduced capacity to recruit macrophages (18). The chemokine seems to be expressed in both mice and human cochleae $(2,18)$. The present results indicate that fractalkine plays a similar role in the ES to attract macrophages to the epithelium for immune reaction. The verification of chemokine receptor expression in the ES macrophages has not been performed so far.

\section{Expression of MHC Class II in the Endolymphatic Sac and Cochlea}

SIM revealed a strong expression of MHCII in IBA1 cells in the ES. Surprisingly, the macrophages populating the stria vascularis (and spiral ligament) and spiral ganglion also expressed MHCII (Figure 9). These molecules are essential to initiate specific immune responses by presenting antigens to $\mathrm{CD} 4+\mathrm{T}$ helper

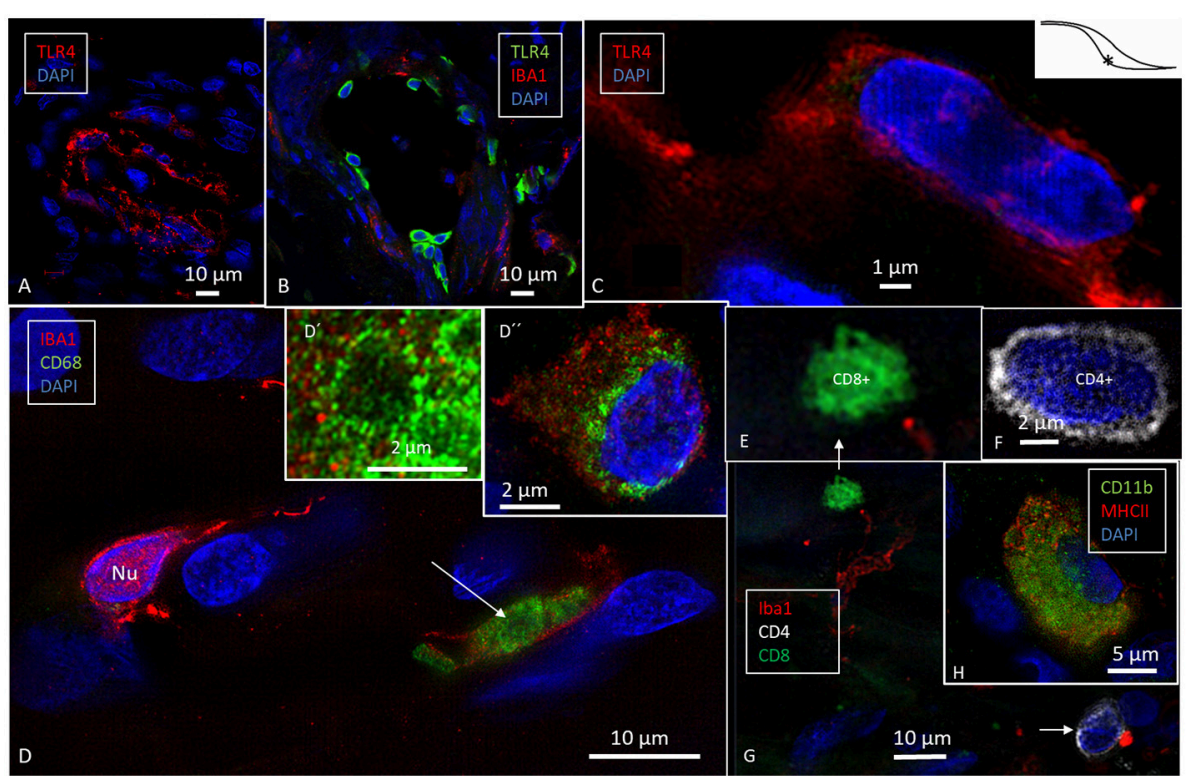

FIGURE 8 | SR-SIM of cells expressing the toll-like receptor 4 (TLR4, A-C), CD68 (D), and CD11b (H) in the human ES. TLR4 is expressed both in the cell membrane and in the cytoplasm (C). (D) CD68 and IBA1 co-expression in the sub-epithelial cells (arrow, inset). Inset $\mathbf{D}^{\prime}$ shows CD68+ cell in a higher magnification and $\mathbf{D}^{\prime \prime}$ shows an IBA1 cell with perinuclear distribution of CD68. (E-G) show sub-epithelial cells expressing lymphocyte markers CD8+ and CD4+ associated with IBA1 cell (arrow, four channels used). (H) One cell co-expresses CD11b and MHCll. *Shows location in the ES. 


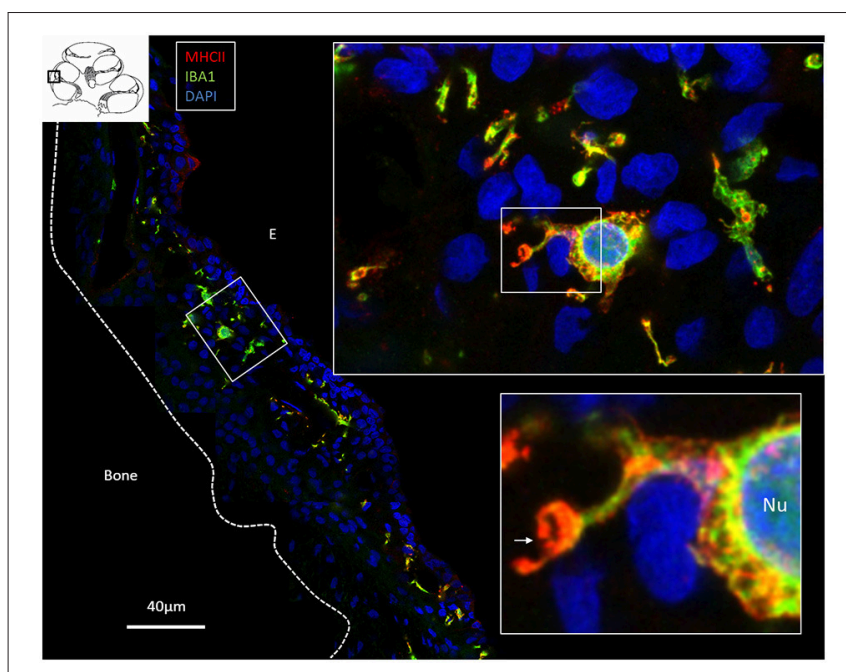

FIGURE 9 | Confocal microscopy and SIM of the human stria vascularis. Cells co-express IBA1 and MHCII. The framed area is magnified in the insets. Several IBA1 cells are located in the stria epithelium, but few are found in the spiral ligament. Insets, The nuclei (Nu) express IBA1. The cell membrane (arrow) and the cytoplasm contain vesicles expressing MHCll. E, Endolymph.

cells and interaction with antigen-specific B cells. Earlier studies showed no MHCII expressing cells in the inner ear, unless induced by experimental inflammation or $\gamma$-interferon $(53,54)$. It seemed consistent with the view that the inner ear lacks immune responsiveness. Okano et al. (20) however, found bone marrow-derived cells, both in the vestibular end organs and the in ES expressing MHCII molecules. Altermatt et al. (55) found a few lymphoid cells expressing MHCII in the epithelial layer in the ES collected post-mortem. Here, MHCII was strongly expressed on the apical cell membrane and vesicles in several tubular epithelial cells. This was remarkable, but it is known that intestinal epithelial cells may express MHCII to play roles in mucosal immunology, modulation, and disease $(56,57)$. These molecules together with antigen cargo can be expressed on the cell surface in thymus epithelial cells (58). In this journal Wosen et al. (59) reviewed existing data on the interaction and regulation of epithelial MHCII molecules in health and disease. Our findings of the co-expression of IBA1 and MHCII in epithelial cells and the trans-epithelial migration propose that there is an uptake and processing of antigens from the ES lumen. Signs of intraepithelial immune cell interaction were earlier demonstrated by transmission electron microscopy (5).

\section{TLR4, CD4, CD68, and CD11b/Integrin Alpha M}

Möller et al. (17) studied the gene expression of the humoral innate immune-system in the human ES and found genes equivalent to that of the mucosa-associated lymphoid tissue (MALT). The expression was verified by immunohistochemistry, suggesting antigen recognition, and processing for the initiation of immune responses. Multiple key elements of both the cellular and humoral innate immune-system were expressed, including toll-like receptors (TLRs) 4 and 7, beta-defensin, and lactoferrin. According to Möller et al. (17), the ES may provide defense not

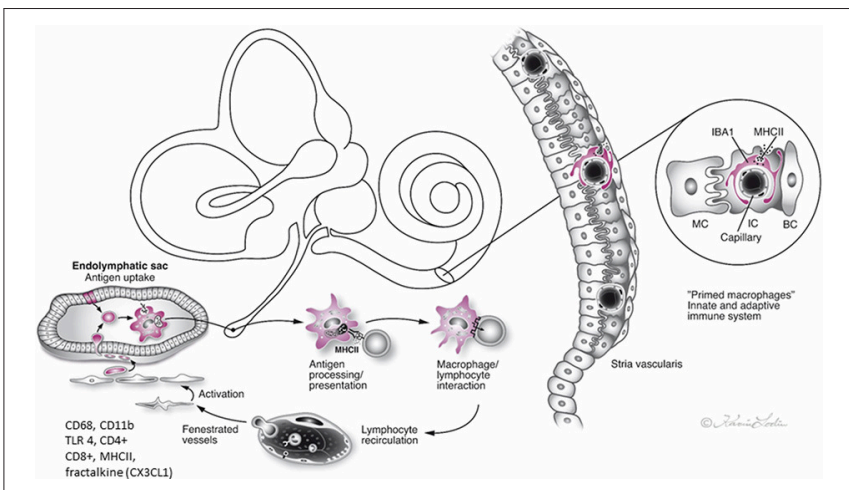

FIGURE 10 | Hypothetical representation of the immune interaction between the endolymphatic sac (ES) and the inner ear in man. The ES receives antigens and waste material via the endolymphatic duct, which activates resident macrophages/monocytes that then migrate into the sac lumen. After phagocytosis, cells migrate back into the perisaccular tissue for antigen presentation and immune processing. MHC class II molecules, reinforced by TLR4, and under IFN $\gamma$ stimuli, bind to endocytosed, and degraded peptides within the cytoplasm and transport the peptides to the cell membrane for presentation to CD4+ T cells. The lymphocytes recirculate into the bloodstream to "prime" the inner ear cells. The immune activation of the inner ear is located "off-site" to avoid pro-inflammatory activation near the vulnerable hair cells. The chemokine fractalkine assists in attracting macrophages to the ES $(2,4,5,10,17)$.

only against bacteria and viruses but also against fungal infection of the inner ear. Altermatt et al. (55) found immunostaining with antibodies against the CD4 and CD8 antigens and revealed a predominance of CD4+ T lymphocytes in the ES. According to Yamada et al. (60), the TLRs 2, 3, 4, and 9 are highly expressed in human ES fibroblasts and can produce cytokines and chemokines in response to the TLR ligands, thereby playing a role during the initiation of immune responses. The findings suggest that the human ES epithelium may trap and engulf intraluminal material reinforced by the TLR 4 signaling. SRSIM also detected both CD4+ and CD8+ cells that also interacted with macrophages. Danckwardt-Lillieström et al. (61) showed ultrastructural evidence of cytotoxic lymphocyte activity in the ES epithelium of a patient with Meniere's disease. It was associated with epithelial cell adhesion and degeneration suggesting that toxic lymphocytes may be directed against own ES cells with on-going autoimmune activity in some cases with this disease.

CD68 was localized in some IBA1-positive cells. CD68 is a $110 \mathrm{kD}$ transmembrane glycoprotein that is highly expressed in human monocytes and tissue macrophages (62). It may promote phagocytosis and recruit macrophages $(63,64)$ and it is widely used as a macrophage marker. CD68 can bind to organ-specific lectins to accomplish these cells homing to particular sites. Macrophages can upregulate CD68 in response to inflammation (65) and can bind to apoptotic cells, possibly exerting antigen processing/presentation. The exact function of CD68 in the inflammatory responses remains somewhat elusive (66). A recent study reported few CD68-positive cells in the ES, mainly in the lumen, while the IBA1-positive cells were more consistent in the ES epithelia and connective tissue (1). The present study seems to have confirmed these findings; CD11b/Integrin alpha $\mathrm{M}$ was also 
expressed in MHCII expressing cells in the ES and spiral ganglion (not shown here). CD11b, also known as macrophage-1 antigen or complement receptor 3 , may bind to molecules on the surface of invading bacteria leading to phagocytosis.

The present investigation shows the large population of macrophages in the human ES. Their capacity for immune processing and their possible links to other cochlear and vestibular macrophages need further elucidation. We speculate that the immune cell machinery in the ES protects the sensory organs, thereby avoiding a full-scale release of pro-inflammatory mediators and antimicrobial activity within the bony enclave of the inner ear (Figure 10). Clearly, more studies are needed to fully understand the function of this hidden and intriguing part of the human inner ear as well as its role in inner ear disease.

\section{CONCLUSIONS}

High-resolution structured illumination microscopy (SR-SIM) was used to analyze the molecular expression of potential immune activity in the ES in the human inner ear. From these results, we conjecture that human hearing and balance organs may be immunologically protected by the ES. Thus, the potentially harmful induction of inflammatory activity near the vulnerable sensory structures may be circumvented.

\section{AUTHOR CONTRIBUTIONS}

Processing of tissue, immune staining and SR-SIM were performed by WL and CN. Most of the writing was

\section{REFERENCES}

1. O'Malley JT, Nadol JB Jr, McKenna MJ. Anti CD163+, Iba1+, and CD68+ Cells in the adult human inner ear: normal distribution of an unappreciated class of macrophages/microglia and implications for inflammatory otopathology in humans. Otol Neurotol. (2016) 37:99-108. doi: 10.1097/MAO.0000000000000879

2. Liu W, Molnar M, Garnham C, Benav H, Rask-Andersen H. Macrophages in the human cochlea: saviors or predators-a study using superresolution immunohistochemistry. Front Immunol. (2018) 9:223. doi: 10.3389/fimmu.2018.00223

3. Mei X, Atturo F, Wadin K, Larsson S, Agrawal S, Ladak HM, et al. Human inner ear blood supply revisited: the Uppsala collection of temporal bone-an international resource of education and collaboration. Ups J Med Sci. (2018) 123:131-42. doi: 10.1080/03009734.2018. 1492654

4. Rask-Andersen H, Stahle J. Lymphocyte-macrophage activity in the endolymphatic sac. An ultrastructural study of the rugose endolymphatic sac in the guinea pig. ORL J Otorhinolaryngol Relat Spec. (1979) 41:177-92. doi: $10.1159 / 000275458$

5. Rask-Andersen H, Stahle J. Immunodefence of the inner ear? Lymphocytemacrophage interaction in the endolymphatic sac. Acta Otolaryngol. (1980) 89:283-94. doi: 10.3109/00016488009127140

6. Tomiyama S, Harris JP. The endolymphatic sac: its importance in inner ear immune responses. Laryngoscope (1986) 96:685-91. doi: 10.1288/00005537-198606000-00018

7. Arnold W, Altermatt HJ, Gebbers JO, Laissue J. Secretory immunoglobulin A in the human endolymphatic sac. An immunohistochemical study. ORL J Otorhinolaryngol Relat Spec. (1984) 46:286-8. doi: 10.1159/0002 75725

8. Bui HT, Linthicum FH Jr, Hofman FM, Bowman CA, House WF. An immunohistochemical study of the endolymphatic sac performed by HR-A and CN. ND-L collected the ES specimens. GL together with HR-A, WL, and CN planned the study.

\section{ACKNOWLEDGMENTS}

This study was supported by ALF and private funds from Börje Runögård, Sweden. We are grateful to SciLife Laboratories and the BioVis Platform at the Uppsala University for providing SR-SIM microscope equipment and for personal support throughout the study. We would also like to thank Karin Lodin for her skillful artwork. This study was partly supported by Medel, Inc., Innsbruck, Austria.

\section{SUPPLEMENTARY MATERIAL}

The Supplementary Material for this article can be found online at: https://www.frontiersin.org/articles/10.3389/fimmu. 2018.03181/full\#supplementary-material

Supplementary Figure 1 | SR-SIM of cell interaction in the sub-epithelial space of the human ES near the external aperture of the vestibular aqueduct (VA). (A) An elongated IBA1 cell physically interacting with a cell expressing MHCII. The framed area is shown under higher magnification in inset $\mathbf{A}^{\prime}$. Both cells' nuclei (Nu) show different protein concentrations. The cell membranes express $\mathrm{MHCll}$. A similar interaction is visible in $\mathbf{A}^{\prime \prime}$. (B) A sub-epithelial macrophage shows intracytoplasmic expression of $\mathrm{MHCll}$. The framed area is magnified in $\mathrm{E}$ and shows globular protein expression. (C) A long sheet of interacting flat cells co-express IBA1 and MHCII near the luminal region of the ES. (D) A sub-epithelial macrophage shows membrane expression of MHCII. (E) Higher magnification of framed area in $\mathbf{B}$.

in patients with acoustic tumors. Laryngoscope (1989) 99:775-8. doi: 10.1288/00005537-198908000-00001

9. Ikeda M, Morgenstern C. Immune response of the endolymphatic sac to horseradish peroxidase: immunologic route from the middle ear to the inner ear. Ann Otol Rhinol Laryngol. (1989) 98:975-9. doi: $10.1177 / 000348948909801211$

10. Tomiyama S, Harris JP. The role of the endolymphatic sac in inner ear immunity. Acta Otolaryngol. (1987) 103:182-8. doi: $10.3109 / 00016488709107271$

11. Danckwardt-Lilliestrom N, Friberg U, Rask-Andersen H. Microorganism transport in the human endolymphatic duct. ORL J Otorhinolaryngol Relat Spec. (1992) 54:211-4. doi: 10.1159/000276300

12. Tomiyama S, Harris JP. Elevation of inner ear antibody levels following direct antigen challenge of the endolymphatic sac. Acta Otolaryngol. (1989) 107:202-9. doi: 10.3109/00016488909127499

13. Harris JP. Immunology of the inner ear: response of the inner ear to antigen challenge. Otolaryngol Head Neck Surg. (1983) 91:18-32. doi: $10.1177 / 019459988309100105$

14. Harris JP, Ryan AF. Immunobiology of the inner ear. Am J Otolaryngol. (1984) 5:418-25. doi: 10.1016/S0196-0709(84)80059-9

15. Harris JP, Ryan AF. Fundamental immune mechanisms of the brain and inner ear. Otolaryngol Head Neck Surg. (1995) 112:639-53. doi: 10.1016/S0194-5998(95)70170-2

16. Pawankar R, Tomiyama S, Jinnouchi K, Ikezono T, Nonaka M, Yagi $\mathrm{T}$. Intercellular adhesion molecule-1 expression in the inner ear of rats following secondary immune reaction in the endolymphatic sac. Acta Otolaryngol Suppl. (1998) 539:5-14. doi: 10.1080/000164898501 82053

17. Moller MN, Kirkeby S, Vikesa J, Nielsen FC, Caye-Thomasen P. Gene expression demonstrates an immunological capacity of the human endolymphatic sac. Laryngoscope (2015) 125:E269-75. doi: 10.1002/lary.25242 
18. Kaur T, Zamani D, Tong L, Rubel EW, Ohlemiller KK, Hirose K, et al. Fractalkine signaling regulates macrophage recruitment into the cochlea and promotes the survival of spiral ganglion neurons after selective hair cell lesion. J Neurosci. (2015) 35:15050-61. doi: 10.1523/JNEUROSCI.232515.2015

19. Okano T, Nakagawa T, Kita T, Kada S, Yoshimoto M, Nakahata T, et al. Bone marrow-derived cells expressing Ibal are constitutively present as resident tissue macrophages in the mouse cochlea. J Neurosci Res. (2008) 86:1758-67. doi: 10.1002/jnr.21625

20. Okano T, Nakagawa T, Ito J. Distribution of bone marrow-derived cells in the vestibular end organs and the endolymphatic sac. Acta Otolaryngol Suppl. (2010) 130:88-94. doi: 10.3109/00016489.2010. 486803

21. Liu W, Li H, Edin F, Brannstrom J, Glueckert R, Schrott-Fischer A, et al. Molecular composition and distribution of gap junctions in the sensory epithelium of the human cochlea-a super-resolution structured illumination microscopy (SR-SIM) study. Ups J Med Sci. (2017) 122:160-70. doi: $10.1080 / 03009734.2017 .1322645$

22. Liu W, Schrott-Fischer A, Glueckert R, Benav H, Rask-Andersen H. The human "Cochlear Battery" - claudin-11 barrier and ion transport proteins in the lateral wall of the cochlea. Front Mol Neurosci. (2017) 10:239. doi: 10.3389/fnmol.2017.00239

23. Rask-Andersen H, Danckwardt-Lilliestrom N, Friberg U, House W. Lymphocyte-macrophage activity in the human endolymphatic sac. Acta Otolaryngol Suppl. (1991) 485:15-7. doi: 10.3109/000164891091 28039

24. Lee-Kubli CA, Ingves M, Henry KW, Shiao R, Collyer E, Tuszynski MH, et al. Analysis of the behavioral, cellular and molecular characteristics of pain in severe rodent spinal cord injury. Exp Neurol. (2016) 278:91-104. doi: 10.1016/j.expneurol.2016.01.009

25. Truman LA, Ford CA, Pasikowska M, Pound JD, Wilkinson SJ, Dumitriu IE, et al. CX3CL1/fractalkine is released from apoptotic lymphocytes to stimulate macrophage chemotaxis. Blood (2008) 112:5026-36. doi: 10.1182/blood-2008-06-162404

26. Gottfried E, Kunz-Schughart LA, Weber A, Rehli M, Peuker A, Muller A, et al. Expression of CD68 in non-myeloid cell types. Scand J Immunol. (2008) 67:453-63. doi: 10.1111/j.1365-3083.2008.02091.x

27. Gonzalez SM, Taborda NA, Correa LA, Castro GA, Hernandez JC, Montoya CJ, et al. Particular activation phenotype of $\mathrm{T}$ cells expressing HLA-DR but not CD38 in GALT from HIV-controllers is associated with immune regulation and delayed progression to AIDS. Immunol Res. (2016) 64:765-74. doi: 10.1007/s12026-0158775-5

28. Yano K, Ohkawa R, Sato M, Yoshimoto A, Ichimura N, Kameda T, et al. Cholesterol efflux capacity of apolipoprotein A-I varies with the extent of differentiation and foam cell formation of THP-1 cells. J Lipids (2016) 2016:9891316. doi: 10.1155/2016/9891316

29. Del Corno M, Donninelli G, Varano B, Da Sacco L, Masotti A, Gessani S. HIV-1 gp120 activates the STAT3/interleukin-6 axis in primary human monocyte-derived dendritic cells. J Virol. (2014) 88:11045-55. doi: 10.1128/JVI.00307-14

30. Lu Z, Xie J, Wu G, Shen J, Collins R, Chen W, et al. Fasting selectively blocks development of acute lymphoblastic leukemia via leptin-receptor upregulation. Nat Med. (2017) 23:79-90. doi: 10.1038/ nm. 4252

31. Bauwens LJ, De Groot JC, Ramaekers FC, Linthicum F, Veldman JE, Huizing EH. Differential immunohistochemical detection of cytokeratins and vimentin in the surgically removed human endolymphatic duct and sac. Eur Arch Otorhinolaryngol. (1991) 248:495-501. doi: 10.1007/BF00627642

32. Liu W, Bostrom M, Kinnefors A, Rask-Andersen H. Unique expression of connexins in the human cochlea. Hear Res. (2009) 250:55-62. doi: 10.1016/j.heares.2009.01.010

33. Burry RW. Controls for immunocytochemistry: an update. $J$ Histochem Cytochem. (2011) 59:6-12. doi: 10.1369/jhc.2010.956920

34. Gustafsson MG, Shao L, Carlton PM, Wang CJ, Golubovskaya IN, Cande WZ, et al. Three-dimensional resolution doubling in wide-field fluorescence microscopy by structured illumination. Biophys J. (2008) 94:4957-70. doi: 10.1529/biophysj.107.120345
35. Sasaki Y, Ohsawa K, Kanazawa H, Kohsaka S, Imai Y. Iba1 is an actin-crosslinking protein in macrophages/microglia. Biochem Biophys Res Commun. (2001) 286:292-7. doi: 10.1006/bbrc.2001.5388

36. Ohsawa K, Imai Y, Kanazawa H, Sasaki Y, Kohsaka S. Involvement of Iba1 in membrane ruffling and phagocytosis of macrophages/microglia. J Cell Sci. (2000) 113 (Pt 17):3073-84.

37. Frick LR, Williams K, Pittenger C. Microglial dysregulation in psychiatric disease. Clin Dev Immunol. (2013) 2013:608654. doi: 10.1155/2013/608654

38. Warchol ME. Macrophage activity in organ cultures of the avian cochlea: demonstration of a resident population and recruitment to sites of hair cell lesions. J Neurobiol. (1997) 33:724-34. doi: 10.1002/(SICI)10974695(19971120)33:6\&lt;724::AID-NEU2\&gt;3.0.CO;2-B

39. Warchol ME, Schwendener RA, Hirose K. Depletion of resident macrophages does not alter sensory regeneration in the avian cochlea. PLoS ONE (2012) 7:e51574. doi: 10.1371/journal.pone.0051574

40. Hirose K, Discolo CM, Keasler JR, Ransohoff R. Mononuclear phagocytes migrate into the murine cochlea after acoustic trauma. J Comp Neurol. (2005) 489:180-94. doi: 10.1002/cne.20619

41. Siddiqui TA, Lively S, Vincent C, Schlichter LC. Regulation of podosome formation, microglial migration and invasion by $\mathrm{Ca}(2+)$-signaling molecules expressed in podosomes. J Neuroinflam. (2012) 9:250. doi: 10.1186/1742-2094-9-250

42. Prinz M, Erny D, Hagemeyer N. Ontogeny and homeostasis of CNS myeloid cells. Nat Immunol. (2017) 18:385-92. doi: 10.1038/ni.3703

43. Hirose K, Rutherford MA, Warchol ME. Two cell populations participate in clearance of damaged hair cells from the sensory epithelia of the inner ear. Hear Res. (2017) 352:70-81. doi: 10.1016/j.heares.2017.04.006

44. Rask-Andersen H, Bagger-Sjoback D, Lundquist PG. The fenestrated blood vessels of the endolymphatic sac. A freeze-fracture and transmission electron microscopic study. Am J Otol. (1983) 4:214-21.

45. Hirose K, Sato E. Comparative analysis of combination kanamycinfurosemide versus kanamycin alone in the mouse cochlea. Hear Res. (2011) 272:108-16. doi: 10.1016/j.heares.2010.10.011

46. Hirose K, Li SZ, Ohlemiller KK, Ransohoff RM. Systemic lipopolysaccharide induces cochlear inflammation and exacerbates the synergistic ototoxicity of kanamycin and furosemide. J Assoc Res Otolaryngol. (2014) 15:555-70. doi: 10.1007/s10162-014-0458-8

47. Fredelius L. Time sequence of degeneration pattern of the organ of Corti after acoustic overstimulation. A transmission electron microscopy study. Acta Otolaryngol. (1988) 106:373-85. doi: 10.3109/00016488809122260

48. Fredelius L, Rask-Andersen $H$. The role of macrophages in the disposal of degeneration products within the organ of corti after acoustic overstimulation. Acta Otolaryngol. (1990) 109:76-82. doi: 10.3109/00016489009107417

49. Tornabene SV, Sato K, Pham L, Billings P, Keithley EM. Immune cell recruitment following acoustic trauma. Hear Res. (2006) 222:115-24. doi: 10.1016/j.heares.2006.09.004

50. Ladrech S, Wang J, Simonneau L, Puel JL, Lenoir M. Macrophage contribution to the response of the rat organ of Corti to amikacin. J Neurosci Res. (2007) 85:1970-9. doi: 10.1002/jnr.21335

51. Yang W, Vethanayagam RR, Dong Y, Cai Q, Hu BH. Activation of the antigen presentation function of mononuclear phagocyte populations associated with the basilar membrane of the cochlea after acoustic overstimulation. Neuroscience (2015) 303:1-15. doi: 10.1016/j.neuroscience.2015.05.081

52. Carrillo SA, Anguita-Salinas C, Pena OA, Morales RA, Munoz-Sanchez $\mathrm{S}$, Munoz-Montecinos C, et al. Macrophage recruitment contributes to regeneration of mechanosensory hair cells in the zebrafish lateral line. J Cell Biochem. (2016) 117:1880-9. doi: 10.1002/jcb.25487

53. Takahashi M, Harris JP. Analysis of immunocompetent cells following inner ear immunostimulation. Laryngoscope (1988) 98:1133-8. doi: 10.1288/00005537-198810000-00018

54. Gloddek B, Ryan AF, Harris JP. Homing of lymphocytes to the inner ear. Acta Otolaryngol. (1991) 111:1051-9. doi: 10.3109/00016489109100755

55. Altermatt HJ, Gebbers JO, Muller C, Arnold W, Laissue JA. Human endolymphatic sac: evidence for a role in inner ear immune defence. ORL J Otorhinolaryngol Relat Spec. (1990) 52:143-8. doi: $10.1159 / 000276124$ 
56. Peterson LW, Artis D. Intestinal epithelial cells: regulators of barrier function and immune homeostasis. Nat Rev Immunol. (2014) 14:141-53. doi: $10.1038 /$ nri3608

57. Lin JT, Kitzmiller TJ, Cates JM, Gorham JD. MHC-independent genetic regulation of liver damage in a mouse model of autoimmune hepatocellular injury. Lab Invest. (2005) 85:550-61. doi: 10.1038/labinvest.3700246

58. Roche PA, Furuta K. The ins and outs of MHC class II-mediated antigen processing and presentation. Nat Rev Immunol. (2015) 15:203-16. doi: $10.1038 /$ nri3818

59. Wosen JE, Mukhopadhyay D, Macaubas C, Mellins ED. Epithelial MHC Class II expression and its role in antigen presentation in the gastrointestinal and respiratory tracts. Front Immunol. (2018) 9:2144. doi: 10.3389/fimmu.2018.02144

60. Yamada T, Ogi K, Sakashita M, Kanno M, Kubo S, Ito Y, et al. Toll-like receptor ligands induce cytokine and chemokine production in human inner ear endolymphatic sac fibroblasts. Auris Nasus Larynx. (2017) 44:398-403. doi: 10.1016/j.anl.2016. 10.007

61. Danckwardt-Lilliestrom N, Friberg U, Kinnefors A, Rask-Andersen H. "Endolymphatic sacitis" in a case of active Meniere's disease. An ultrastructural histopathologic investigation. Ann Otol Rhinol Laryngol. (1997) 106:190-8. doi: 10.1177/000348949710600303

62. Holness CL, da Silva RP, Fawcett J, Gordon S, Simmons DL. Macrosialin, a mouse macrophage-restricted glycoprotein, is a member of the lamp/lgp family. J Biol Chem. (1993) 268:9661-6.
63. Holness CL, Simmons DL. Molecular cloning of CD68, a human macrophage marker related to lysosomal glycoproteins. Blood (1993) 81:1607-13.

64. Kurushima H, Ramprasad M, Kondratenko N, Foster DM, Quehenberger O, Steinberg D. Surface expression and rapid internalization of macrosialin (mouse CD68) on elicited mouse peritoneal macrophages. J Leukoc Biol. (2000) 67:104-8. doi: 10.1002/jlb.67.1.104

65. Rabinowitz SS, Gordon S. Macrosialin, a macrophage-restricted membrane sialoprotein differentially glycosylated in response to inflammatory stimuli. J Exp Med. (1991) 174:827-36. doi: 10.1084/jem.174. 4.827

66. Chistiakov DA, Killingsworth MC, Myasoedova VA, Orekhov AN, Bobryshev YV. CD68/macrosialin: not just a histochemical marker. Lab Invest. (2017) 97:4-13. doi: 10.1038/labinvest.2016.116

Conflict of Interest Statement: The authors declare that the research was conducted in the absence of any commercial or financial relationships that could be construed as a potential conflict of interest.

Copyright (C) 2019 Kämpfe Nordström, Danckwardt-Lillieström, Laurell, Liu and Rask-Andersen. This is an open-access article distributed under the terms of the Creative Commons Attribution License (CC BY). The use, distribution or reproduction in other forums is permitted, provided the original author(s) and the copyright owner(s) are credited and that the original publication in this journal is cited, in accordance with accepted academic practice. No use, distribution or reproduction is permitted which does not comply with these terms. 